\title{
Дегидратация мяса виноградной улитки «Helix pomatia» при исследовании методами ИК-спектроскопии и термического анализа
}

\author{
Глотова И.А. ${ }^{1}$, Кусакина О.С. ${ }^{1}$, Перегончая О.В. ${ }^{1}$, Синяева Л.А. ${ }^{2}$ \\ ${ }^{I}$ Воронежский государственный аграрный университет, Воронеж \\ ${ }^{2}$ ФБОГОУ ВО «Воронежский государственный университет», Воронеж
}

Поступила в редакцию 15.01.2017 г.

\begin{abstract}
Представлены результаты исследования термолиза виноградной улитки «Helix pomatia» методами инфракрасной абсорбционной спектроскопии и термического анализа. Показано, что высушивание до постоянной массы приводит к практически полному удалению воды из мяса виноградной улитки. Проведен кинетический анализ стадий дегидратации.
\end{abstract}

Ключевые слова: виноградная улитка, инфракрасная абсорбционная спектроскопия, сушка, дегидратация, термолиз

\section{Dehydration of meat of grape snail «Helix pomatia» researched by IR spectroscopy and thermal analysis techniques}

\author{
Glotova I.A. ${ }^{1}$, Kusakina O.S. ${ }^{1}$, Peregonchaya O.V. ${ }^{1}$, Sinyaeva L.A. ${ }^{2}$ \\ ${ }^{l}$ Voronezh State Agrarian University, Voronezh \\ ${ }^{2}$ Voronezh State University, Voronezh
}

\begin{abstract}
Grape snail «Helix pomatia» is a valuable raw material for bioprocessing. Its meat is rich in protein with a unique set of amino acids. The drying stage is required due to the high humidity of this product. The selection of temperature conditions of drying is relevant. The research results of thermolysis of «Helix pomatia» grape snail meat were presented in this article. Infrared absorption spectroscopy (IRS) and differential scanning colorimetry (DSC) methods were used. When samples heating to $60-70^{\circ} \mathrm{C}$ their protein structure don't disturb, this fact was reaserched by the method of IRS identified. Thermolysis athigher temperatures leads to the destructio of the protein secondary structure and partial decomposition of the organic components. The kinetic analysis of the dehydration product was accomplished as a result of using DSC technique. The formal mechanism of the process was determined. The values of effective activation energies of stages of dehydration were calculated. The desiccation to constant weight leads to the almost complete removal of water from meat of grape snail. The desiccation in order conservation of biological values of raw materials and the quality of the food is advantageously carried out at temperatures less than $60^{\circ} \mathrm{C}$.
\end{abstract}

Keywords: snail, infrared absorption spectroscopy, drying, dehydration, thermolysis

\section{Введение}

Виноградная улитка «Helix pomatia» - уникальное сырье для биопереработки. Мясо улитки содержит до 70\% белка в пересчете на сухое вещество, богатого остатками таких аминокислот как лейцин, аргинин, глутаминовой и аспаргиновой кислотами [1]. Гелицекультура является перспективным направлением развития нетрадиционных объектов сельскохозяйственного воспроизводства [2-3]. 
Мясо улитки является продуктом высокой влажности, содержание воды в его структуре около 80\%, поэтому важным этапом в комплексной переработке виноградной улитки является ее дегидратация. Для удаления влаги из продуктов используют разные способы, но наиболее распространенным является конвективная сушка. От условий осуществления процесса сушки зависят важнейшие качественные показатели продукта переработки объектов гелицекультуры. Поэтому целью данной работы было установление механизма и кинетики процессов, протекающих в образце при повышении температуры.

\section{Эксперимент}

Закономерности теплового воздействия на мясное сырье исследовали методами инфракрасной абсорбционной спектроскопии [4] и термического анализа. При подготовке к исследованиям методом инфракрасной (ИК) абсорбционной спектроскопии образец мяса улитки высушивали до постоянной массы при температурах в диапазоне от 30 до $105^{\circ} \mathrm{C}$. Затем из навесок высушенных образцов готовили таблетки с $\mathrm{KBr}$ по методике [5]. Спектрограммы записывали на спектрометре ИКС-29 с интегрирующей сферой в области 4000-650 $\mathrm{cm}^{-1}$.

Для выяснения особенностей удаления воды из мяса улиток в неизотермических условиях использовали метод дифференциальной сканирующей калориметрии (ДСК). Исследования проводили на приборе синхронного термического анализа модели STA 449 F3 Jupiter в алюминиевом тигле с проколотой крышкой (в качестве эталона использовался пустой алюминиевый тигель с проколотой крышкой), измерения проводились в среде азота класса 5.0 (расход газа $20 \mathrm{~cm}^{3} / \mathrm{Mин)} \mathrm{в} \mathrm{интервале}$ температур от 25 до $200^{\circ} \mathrm{C}$ со скоростью нагрева 2 градуса/мин, масса навески составляла 11.81 мг.

\section{Обсуждение результатов}

При исследовании термолиза белков и полипептидных структур методом ИКспектроскопии наибольший интерес представляют полосы поглощения, отвечающие частотам валентных колебаний связей N-H с $v_{\max } \sim 3300 \mathrm{~cm}^{-1}$ и $\mathrm{C}=\mathrm{O}$ с $v_{\max } \sim 1650$ $1630 \mathrm{~cm}^{-1}$ (полоса амид I), а также деформационных колебаний N-H в амидной группе с $v_{\max } \sim 1520-1550 \mathrm{~cm}^{-1}$ (полоса амид II) и $v_{\max } \sim 1350-1200 \mathrm{~cm}^{-1}$ (полоса амид III) [6, 7]. В таблице 1 приведены значения волновых чисел, соответствующих полосам поглощения образцов после высушивания до постоянной массы при разной температуре.

Таблица 1 Основные волновые числа полос поглощения пептидных связей белков мяса виноградной улитки Helix pomatia после высушивания при разных температуpax

\begin{tabular}{|c|c|c|c|c|c|c|}
\hline \multirow{2}{*}{ Колебание } & \multicolumn{5}{|c|}{ Волновые числа $\left(\mathrm{cm}^{-1}\right)$ полос поглощения для образцов, } \\
& $30^{\circ} \mathrm{C}$ & $40^{\circ} \mathrm{C}$ & $50^{\circ} \mathrm{C}$ & $60^{\circ} \mathrm{C}$ & $70^{\circ} \mathrm{C}$ & $105^{\circ} \mathrm{C}$ \\
\hline & 3280 & 3278 & 3280 & 3273 & - & - \\
\hline $\mathrm{N}-\mathrm{H}$ & 1641 & 1641 & 1633 & 1635 & $1633-1645$ & $1635-1645$ \\
\hline $\begin{array}{c}\mathrm{C}=\mathrm{O} \\
\text { Амид I }\end{array}$ & 1539 & 1539 & 1539 & 1539 & 1539 & 1539 \\
\hline $\begin{array}{c}\text { С - N - H } \\
\text { Амид II }\end{array}$ & 1236 & 1236 & 1238, & 1234, &,- &,- \\
\hline $\begin{array}{c}\text { С - N - H } \\
\text { Амид III }\end{array}$ & - & - & 1315 & 1328 & 1330 & 1330 \\
\hline
\end{tabular}


После высушивания образцов при 30,40 и $50^{\circ} \mathrm{C}$ на спектрограммах наблюдается широкий и единственный максимум поглощения $3280 \mathrm{~cm}^{-1}$ (табл. 1), характерный для колебаний растяжения связи $\mathrm{N}-\mathrm{H}$. Наличие данной полосы поглощения в спектре может говорить о существовании $\beta$-слоев вторичной структуры белка [6]. При повышении температуры сушки до $60^{\circ} \mathrm{C}$ этот максимум существенно уменьшается и сдвигается до $3273 \mathrm{~cm}^{-1}$, а при высушивании при 70 и $105^{\circ} \mathrm{C}$ полностью исчезает (табл. 1). Подобное спектральное поведение может свидетельствовать о частичном нарушении $\beta$-слоев в интервале температур $50-60^{\circ} \mathrm{C}$ и разрушении нативной структуры белка при более высоких температурах. Обращает на себя внимание отсутствие характерных для этой области электромагнитного спектра полос поглощения валентных колебаний связи О-Н, что свидетельствует о практически полном удалении воды из образцов при высушивании до постоянной массы.

Полосы поглощения в спектральном диапазоне амид III являются в основном результатом комбинации деформационных колебаний в плоскости связи N-H и деформационного колебания растяжения связи C-N и они крайне чувствительны к изменениям вторичной структуры белка. Спектрограммы образцов, высушенных при 30 и $40^{\circ} \mathrm{C}$, содержат полосу поглощению $1236 \mathrm{~cm}^{-1}$, соответствующую существованию $\beta$-слоев в структуре белка (табл. 1). Повышение температуры сушки приводит к разрушению межмолекулярных водородных связей и частичной денатурации белковой структуры образца. На спектральных характеристиках образцов, высушенных при 70 и $105^{\circ} \mathrm{C}$ присутствует только полоса $1330 \mathrm{~cm}^{-1}$, соответствующая существованию белков в форме $\alpha$-спирали (табл. 1$)$.

Полосы амид I и амид II не претерпевают существенных изменений при нагревании образцов в исследуемом температурном интервале, что свидетельствует о сохранении первичной структуры белка. Однако относительное уменьшение интенсивности полосы амид II в спектрах образцов, высушенных при 70 и $105^{\circ} \mathrm{C}$, может свидетельствовать о деградационных изменениях в структуре боковых цепей аминокислотных остатков.

Представляло интерес исследовать кинетику удаления воды из фазы образцов мяса виноградной улитки методом ДСК. В современном виде методы термического анализа являются высокочувствительными и совершенными методами исследования конденсированных, в том числе гетерогенных систем, позволяющими определять термодинамические параметры процесса термолиза различных объектов (теплоёмкость, температура и энтальпия фазовых и структурных переходов) и кинетические характеристики процессов в условиях изменения температуры.

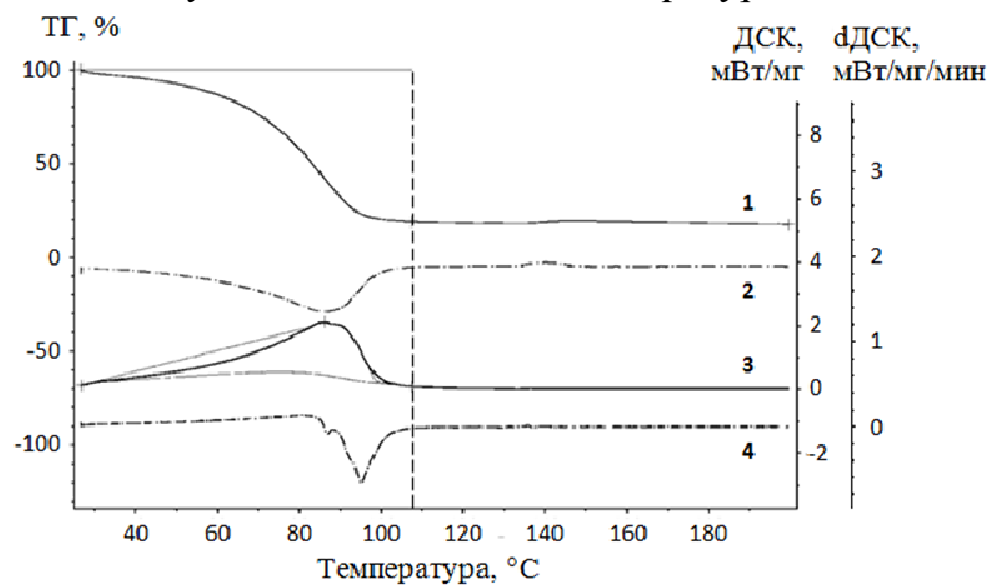

Рис. 1. Дериватограмма мяса виноградной улитки Helix pomatia. Кривые: 1 - ТГ, 2 - ДТГ, 3 - ДСК, 4 - dДСК. 
На рисунке 1 представлена дериватограмма образца мяса виноградной улитки Helix pomatia. Потеря массы образца в интервале температур $30-107{ }^{\circ} \mathrm{C}$ связана с удалением воды (рис.1, кр.1). На кривой 3 наблюдается эндотермический максимум, соответствующий превращениям в температурном интервале от 82.6 до $98.6^{\circ} \mathrm{C}$. Совместное протекание физико-химических процессов дегидратации и денатурации белка характеризуется величиной площади комплексного пика на кривой 3 (рис.1) равной 1226 Дж/г и пропорциональной тепловому эффекту.

Тепловое воздействие на образец приводит к значительным изменениям, в результате которых удаляется вода, происходит термический распад белков, жиров, углеводов [6-9]. В результате масса образца снижается. Кинетические характеристики потери массы определяют по экспериментальной термогравиметрической кривой, отражающей изменение массы образца по мере протекания термолиза.

Малая скорость нагрева, а также небольшой температурный интервал, в котором происходит дегидратация, позволяют применить для описания этого процесса положения изотермической кинетики. Для оценки механизма и величины кинетических параметров процесса удаления воды из фазы исследованных образцов применяли метод, основанный на связи степени превращения вещества $(\alpha)$ и времени $(\tau)$. Величину $\alpha$ рассчитывали по кривым потери массы образца во времени (рис. 1 , кр. 1) как отношение количества удаленной при данной температуре воды к общему количеству удаляемого компонента.

Анализ зависимости скорости дегидратации образца $\mathrm{d} \alpha / \mathrm{d} \tau$ от времени термолиза (рис. 2а) показывает, что удаление воды происходит в три этапа. Это подтверждает вид зависимости $-\lg \alpha$ от величины обратной температуры $(1 / \mathrm{T})$, представленной на рис.2б.
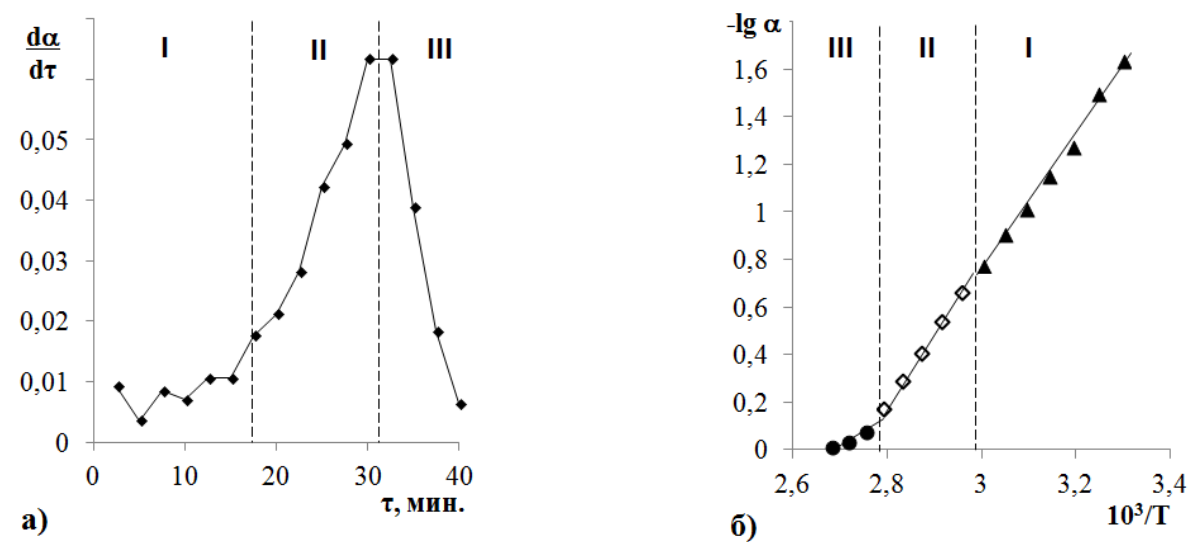

Рис. 2. Кинетические зависимости: а) зависимость скорости дегидратации $(\mathrm{d} \alpha / \mathrm{d} \tau)$ от времени термолиза $(\tau) ;$ б) зависимость степени превращения $(\alpha)$ от температуры (T, K). I-III - стадии термолиза.

Для получения информации о механизме и кинетических параметрах стадий процесса удаления воды использовали закономерности кинетики твердофазных превращений [9-11]. Выбор кинетического уравнения для каждой стадии дегидратации в соответствии с наиболее вероятным механизмом ее протекания проводили с использованием формальных механизмов гетерогенных процессов, предложенных в монографии Я.Шестака $[9,10]$ по методике изложенной в работе [11]. Для каждого использованного кинетического уравнения получали значения $\operatorname{tg} \varphi(\varphi$ - угол наклона прямой к оси абсцисс) и коэффициента корреляции для функции $\mathrm{g}(\alpha)$ в области линейности. Из нескольких опробованных кинетических уравнений выбирали то, для которого коэффициент корреляции был максимален. Энергию активации каждой ста- 
дии дегидратации Еа, кДж/моль, рассчитывали по методу Ахары и Шарпа, исходя из величин $\operatorname{tg} \varphi: \mathrm{Ea}=2.3 \mathrm{R} \cdot \operatorname{tg} \varphi$. Вид функции $\mathrm{g}(\alpha)$ и значения эффективной энергии активации указаны в таблице 2 .

Таблица 2. Кинетические параметры процесса дегидратации мяса виноградной улитки Helix pomatia

\begin{tabular}{|c|c|c|c|c|c|}
\hline Стадии & $\Delta \mathrm{T}$ & $\Delta \alpha$ & $\mathrm{m}$ & $\mathrm{g}(\alpha)$ & $\mathrm{Ea}$ \\
\hline I & $30-60$ & $0-0.167$ & 13.6 & {$[-\lg (1-\alpha)] 1 / 4$} & 13.8 \\
II & $60-85$ & $0.167-0.678$ & 41.4 & {$[-\lg (1-\alpha)] 1 / 4$} & 27.6 \\
III & $85-105$ & $0.678-0.995$ & 25.7 & {$[-\lg (1-\alpha)] 1 / 4$} & 51.4 \\
\hline
\end{tabular}

$\Delta \mathrm{t}$ - интервал температур, ${ }^{\circ} \mathrm{C} ; \Delta \alpha$ - интервал степени превращения; $\mathrm{m}$ - масса воды, удаляемой на стадии дегидратации, \% от массы образца; $\mathrm{g}(\alpha)$ - вид кинетического уравнения процесса; $\mathrm{E}_{\mathrm{a}}-$ энергия активации, кДж/моль.

Согласно полученным данным удаление воды из образца мяса виноградной улитки Helix pomatia на каждой стадии описывается кинетическим уравнением процесса образования зародышей, что указывает на отсутствие химических и диффузионных трудностей при протекании дегидратации и косвенно подтверждается данными ИК-спектроскопии.

Нагревание образца в интервале температур $30-60^{\circ} \mathrm{C}$ сопровождается удалением наиболее кинетически активных молекул воды, обладающих малой степенью ассоциации. Для этой стадии процесса характерно самое низкое значение энергии активации 13.8 кДж/моль. На второй стадии в интервале температур $60-85{ }^{\circ} \mathrm{C}$ разрушаются межмолекулярные водородные связи водных ассоциатов и удаляется основная масса воды, а также происходит разрушение нативной структуры белковых молекул. Эффективная энергия активации процесса увеличивается до значения 27.6 кДж/моль. Нагревание образца до $105^{\circ} \mathrm{C}$ сопровождается удалением наиболее прочно связанных друг с другом и с материалом образца молекул воды, а также сопровождается развитием процесса денатурации белка и термического разложения органических компонентов, вследствие чего эффективная энергия активации возрастает до 51.4 кДж/моль.

Полученные результаты свидетельствуют о дегидратации мяса виноградной улитки Helix pomatia как о сложном многостадийном процессе, сопровождающемся денатурацией белковой структуры образца при температурах выше $70^{\circ} \mathrm{C}$. Для сохранения биологической ценности сырья и качества пищевого продукта реализацию сушки данного объекта целесообразно осуществлять при температурах до $60^{\circ} \mathrm{C}$.

Экспериментальные исследования были проведены на базе центтов коллективного пользования ВГУ и ВГУИТ.

\section{Список литературы}

1. Глотова И. А., Кусакина О. С., Шахов С. В., Куралесина В. Н. // Международный студенческий научный вестник. 2015. № 33. С. 348-349.

2. Гайнуллин Р.Р. // Молодой ученый. 2009. № 12. С. 117-122.

3. Кусакина О.С., Глотова И.А., Глущенко А.А. // Современные наукоемкие технологии. 2014. № 5-1. C. 188-189.
4. Глотова И.А., Перегончая О.В., Кусакина О.С. // «Теоретические и практические вопросы интеграчии химической науки, технологии и образования», сборник трудов Всероссийской конференции, 20 апреля 2016 г. г. Улан-Удэ. 2016. C. $40-45$.

5. Углянская В. А., Чикин Г. А., Селеменев В. Ф., Завьялова Т. А. Инфракрасная спектроскопия ионообменных материалов. Воронеж: Издательство ВГУ. 1989. 208 с. 
6. Кантор Ч., Шиммел П. Биофизическая химия: В 3-х т. Пер. с англ. М. Мир. 1984. T.2. $496 \mathrm{c}$

7. Дехант И. Инфракрасная спектроскопия полимеров. Пер. с нем. М. Мир. 1965. 210 с.

8. Нечаев А. П. Пищевая химия. С.-Пб. Гиорд. $2001.581 \mathrm{c}$.

\section{References}

1. Glotova I.A., Kusakina O.S., Shahov S.V., Kuralesina V.N., International Student Scientific Bulletin, 2015, № 3-3, pp. 348-349.

2. Gainullin R.R., Young scientist, 2009, No 12, pp. 117-122.

3. Kusakina O.S., Glotova I.A., Glushchenko A.A., Modern high technologies, 2014, No 5-1, pp. 188-189.

4. Glotova I.A., Peregonchaya O.V., Kusakina O.S., «Theoretical and practical problem integration of chemical sience, technology and education», Proceedings Conference, 2016, pp. 40-45.

5. Uglyanskaya V.A., Chirkin G.A., Selemenev V.F., Zavyalova T.A. Infrared spectroscopy of ion exchange materials, Voronezh, publishing house VSU, 1989, 208 p.

Глотова Ирина Анатольевна - д-р техн. наук, профессор Воронежского ГАУ, Воронеж

Перегончая Ольга Владимировна - канд. хим. наук, доцент Воронежского ГАУ , Воронеж

Кусакина Оксана Семеновна - аспирант Воронежского ГАУ, Воронеж

Синяева Лилия Александровна - аспирант кафедры аналитической химии ВГУ, Воронеж
9. Шестак Я. Теория термического анализа. М. Мир. 1987. $456 \mathrm{c.}$

10. Розовский А. Я. Кинетика топохимических реакиий. М. Химия, 1974. 256 с.

11. Перегончая О. В., Тертычная Т. Н. // Сорбиионные и хроматографические проuесcы. 2011. T. 11. № 4. С. 511-517.

6. Kantor Ch., Shimmel P. Biophysical chemistry: in three volumes, M., Mir, 1984, Vol. 2, $496 \mathrm{p}$.

7. Dekhant I., Infrared spectroscopy of polymers, M., Mir, 1965, 210 p.

8. Nechaev A.P., Food chemistry , S.-Pb., Giord,2001, $581 \mathrm{p}$.

9. Shestak I., Theory thermal analysis, M., Mir, 1987, $456 \mathrm{p}$.

10. Rozovskiy A.I., The kinetics of the topochemically reactions, M., Chemistry, 1974,256 p.

11. Peregonchaya O.V., Tertiychnay T.N., Sorbtsionnye i khromatograficheskie protsessy, 2011, Vol. 11, No 4, pp. 511-517.

Glotova Irina A. - prof., grand Ph.D (engineering), department of processing of animal husbandry products VSAU, Voronezh, E-mail: glotovairina@yandex.ru

Peregonchaya Olga V., Ph.D. (chemistry), associate prof., department of chemistry VSAU, Voronezh, E-mail: ovp177@yandex.ru

Kusakina Oksana S., the postgraduate student, department of processing of animal husbandry products VSAU, Voronezh, E-mail: departamentkusakina@yandex.ru

Siniaeva Liliia A., the postgraduate student, departament of analytical chemistry, VSU,Email: liliya.sinyaevavsu@mail.ru 